\title{
CORRECTION
}

\section{Correction to: An effective approach for the dual-resource flexible job shop scheduling problem considering loading and unloading}

\author{
Xiuli $\mathrm{Wu}^{1} \cdot$ Junjian Peng ${ }^{1} \cdot$ Xiao Xiao ${ }^{1} \cdot$ Shaomin $W^{2}$
}

Published online: 29 October 2021

๑) Springer Science+Business Media, LLC, part of Springer Nature 2021

\section{Correction to:}

Journal of Intelligent Manufacturing (2021) 32:707-728

https://doi.org/10.1007/s10845-020-01697-5

Due to a slip, which mixed up two folds storing data on two sets of different algorithms, the original version of this article unfortunately contained some mistakes. The original experiment results (Table 7) in Case Study were uploaded incorrectly. Algorithm C in Table 5 is obtained from the first instance in Table 7, so Table 5 needs to be revised. Figures 10, 13 and 14 are to show the Pareto solutions and the Gantt Charts of the best solution and need to be revised. Figure 17 is to show the Pareto solutions of each instance (Table 7) obtained with MODE and the improved NSGA-II, respectively and needs to be revised.
The corrected version is given below. For each item, the original and the corrected are given in the following table, respectively. From these comparisons, we can see that the corrected results support the conclusion much more.

Original article has been corrected.

The original article can be found online at https://doi.org/10.1007/s10 845-020-01697-5.

\footnotetext{
Shaomin $\mathrm{Wu}$

s.m.wu@kent.ac.uk

1 University of Science and Technology Beijing, Beijing, China

2 University of Kent, Canterbury CT2 7FS, UK
} 
1182

Journal of Intelligent Manufacturing (2022) 33:1181-1188

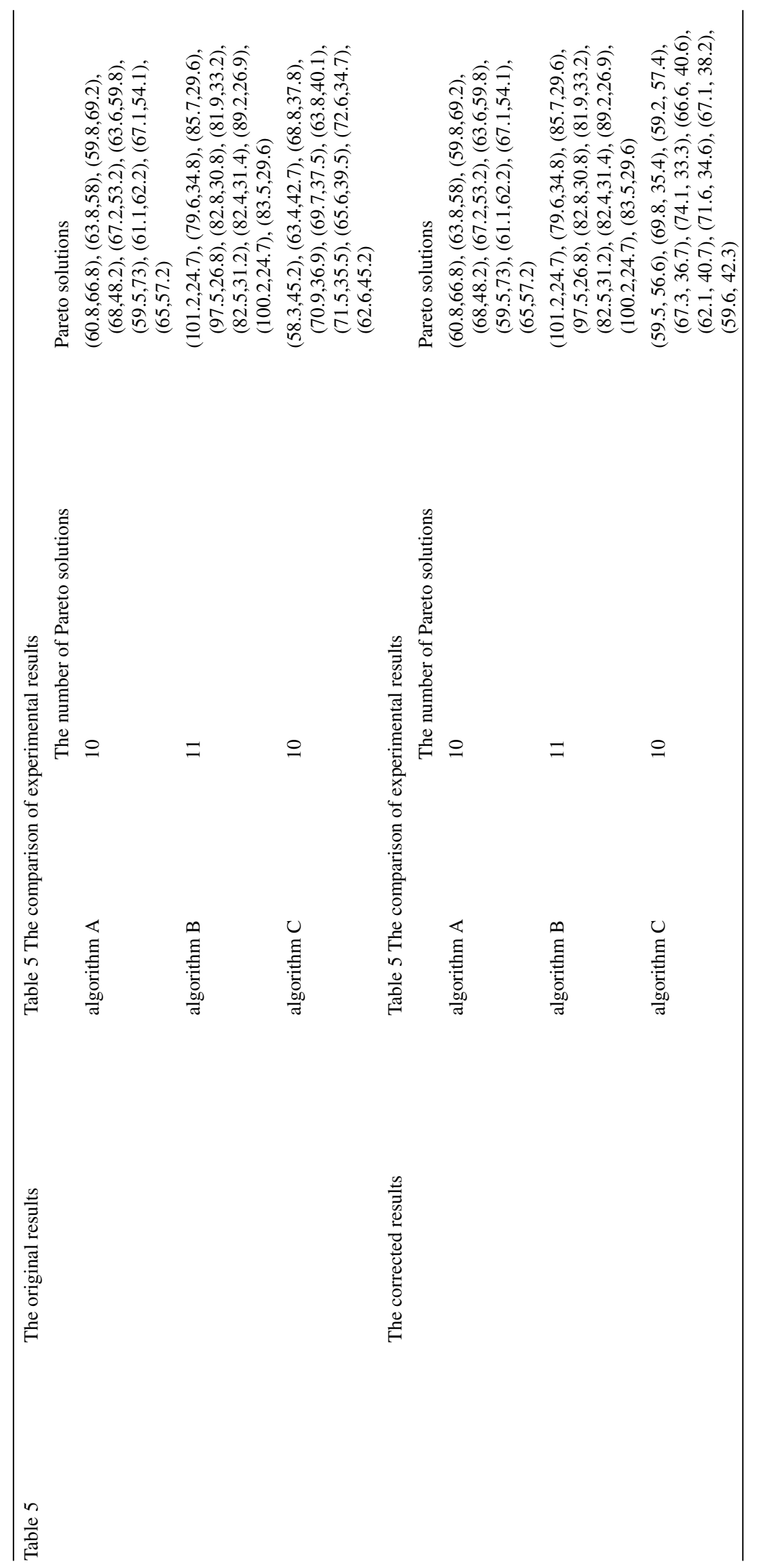

Springer 
Journal of Intelligent Manufacturing (2022) 33:1181-1188

1183

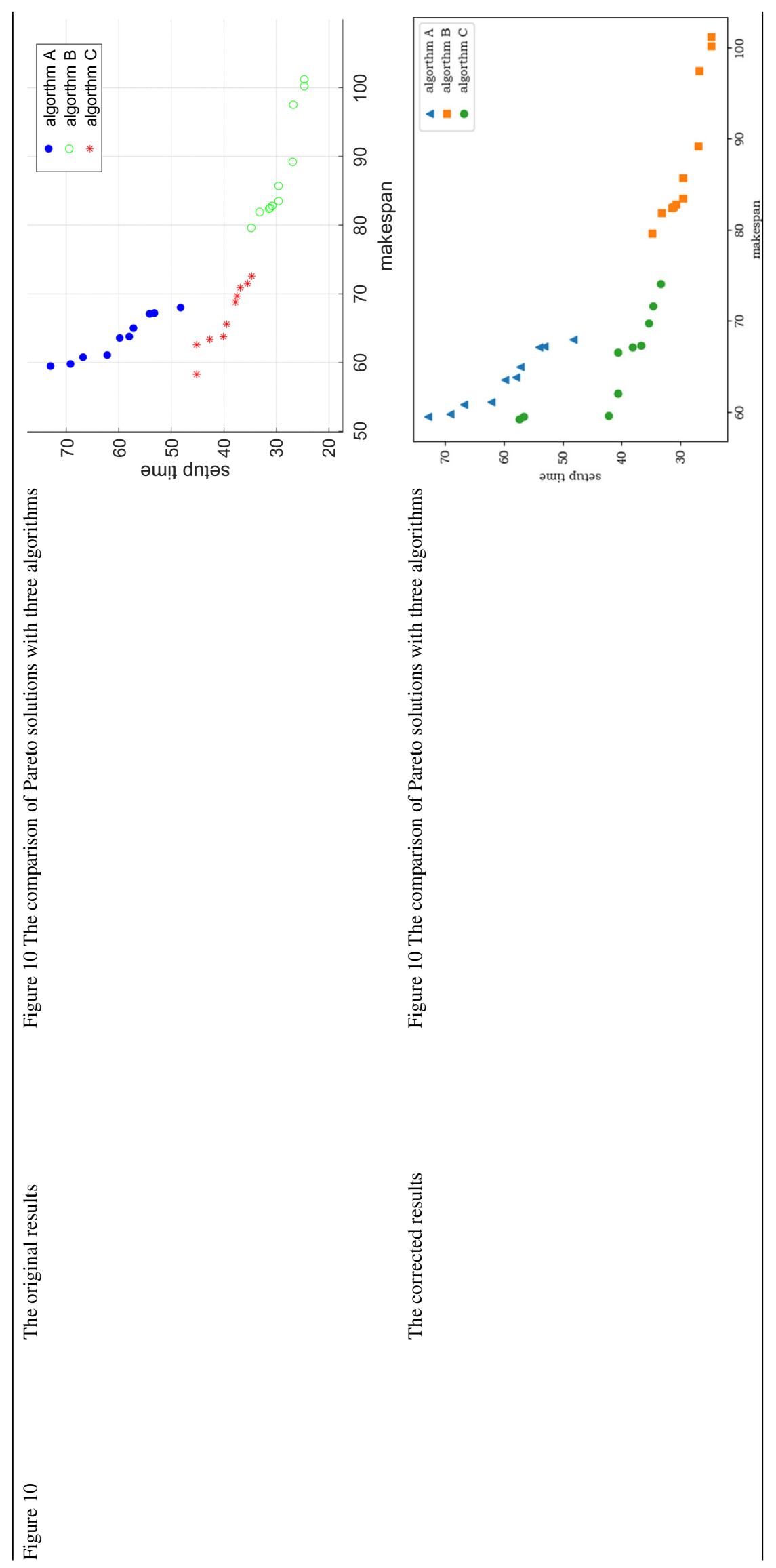

Springer 

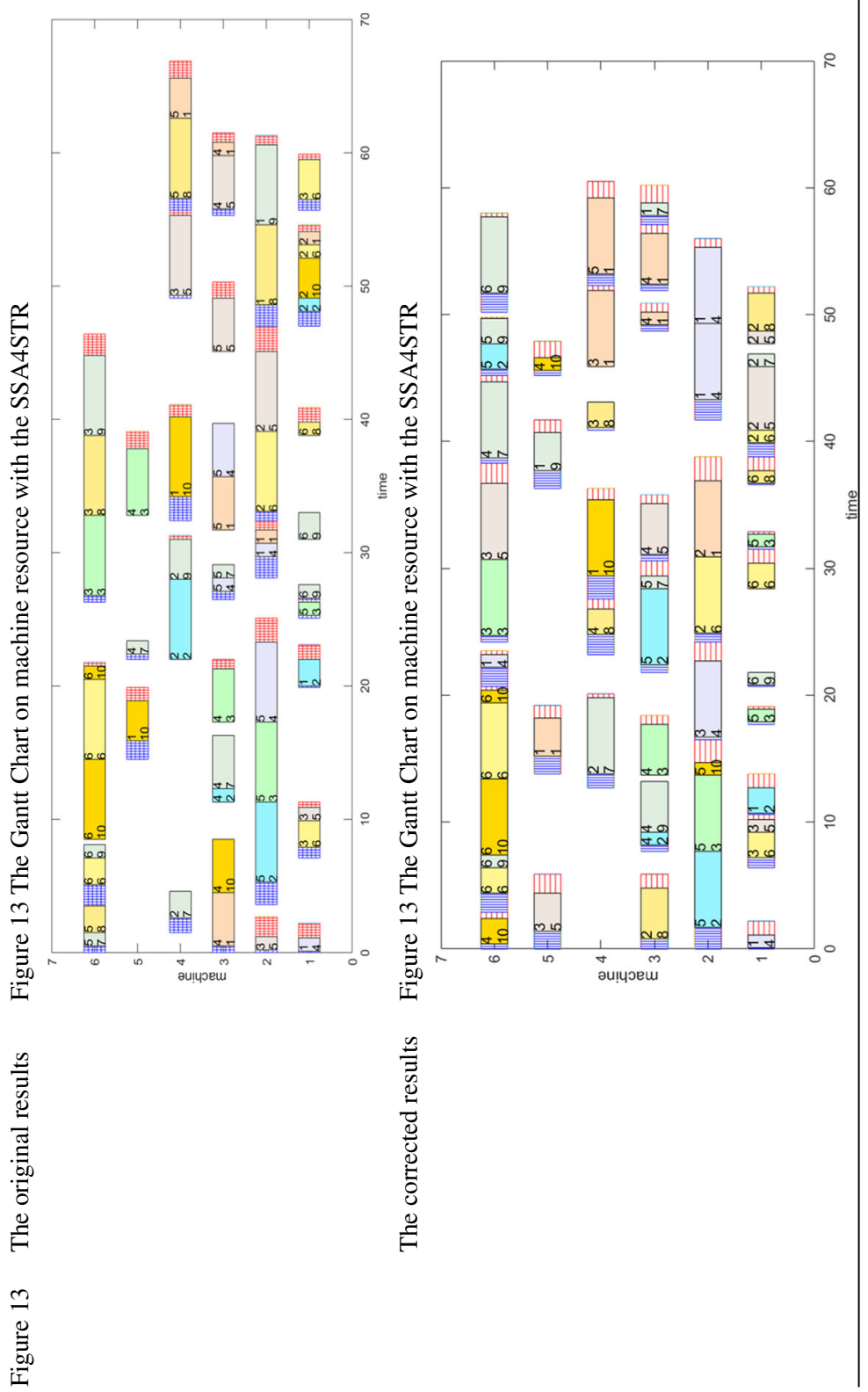

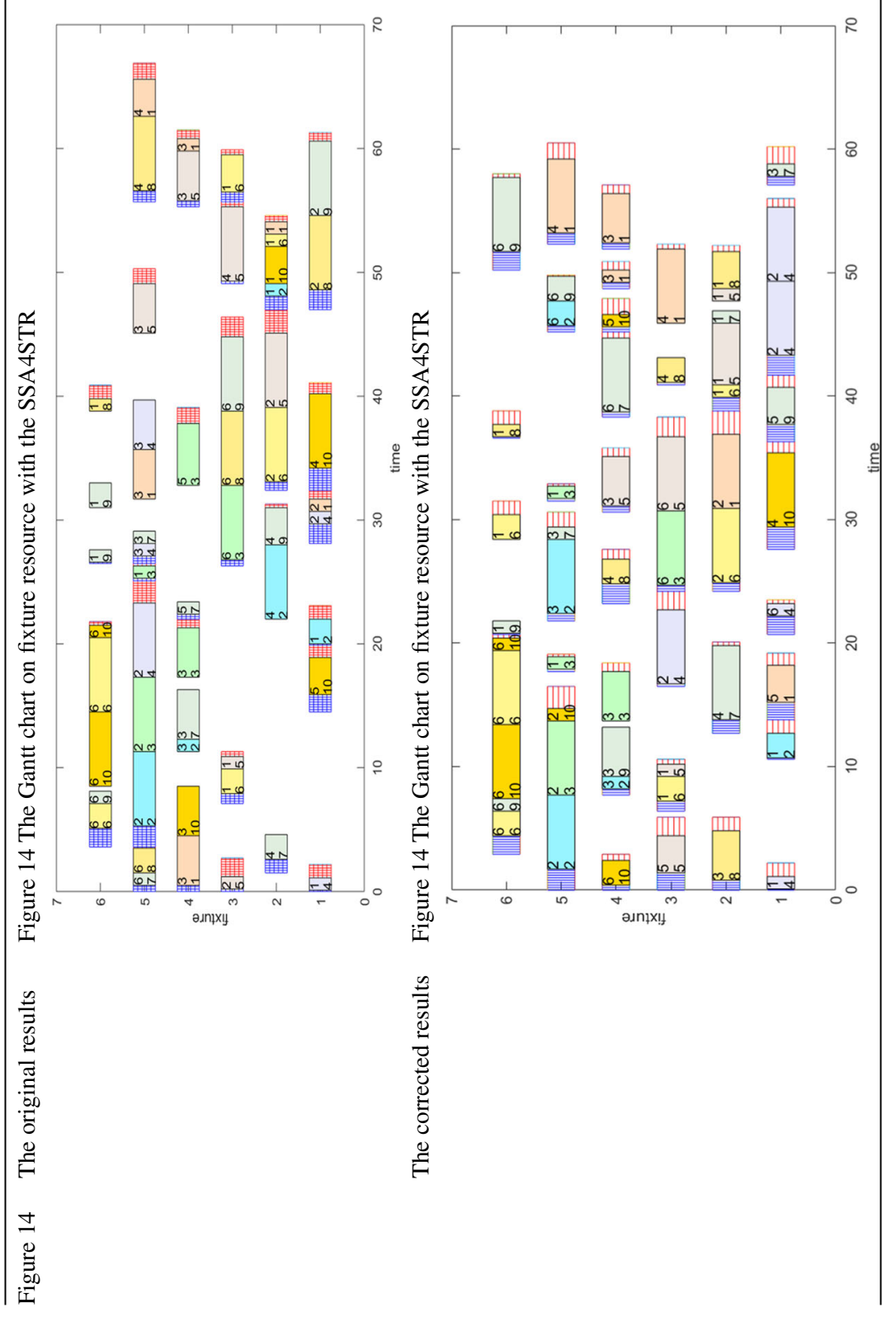


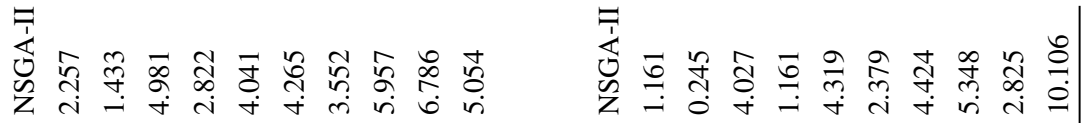

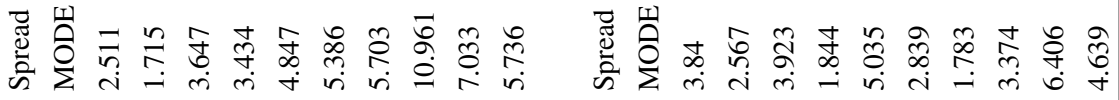

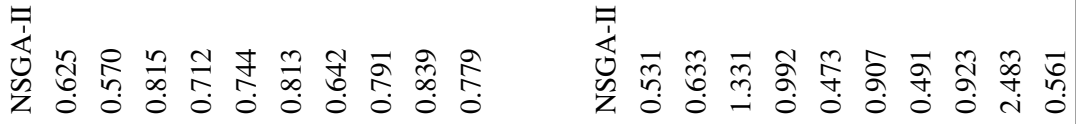

$\stackrel{\Xi}{\Xi}$

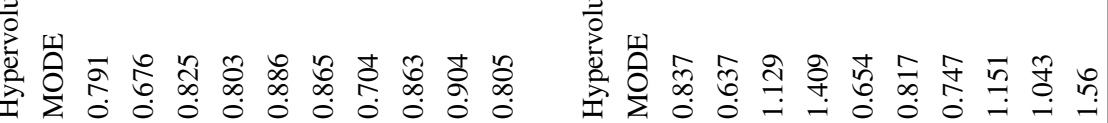

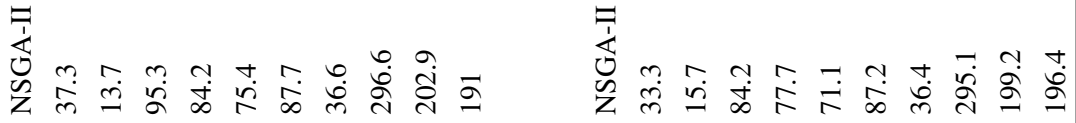

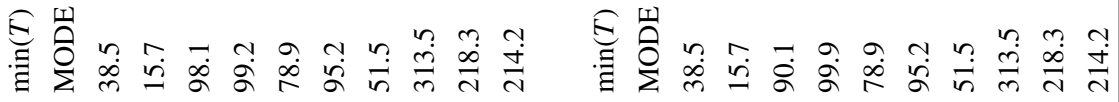

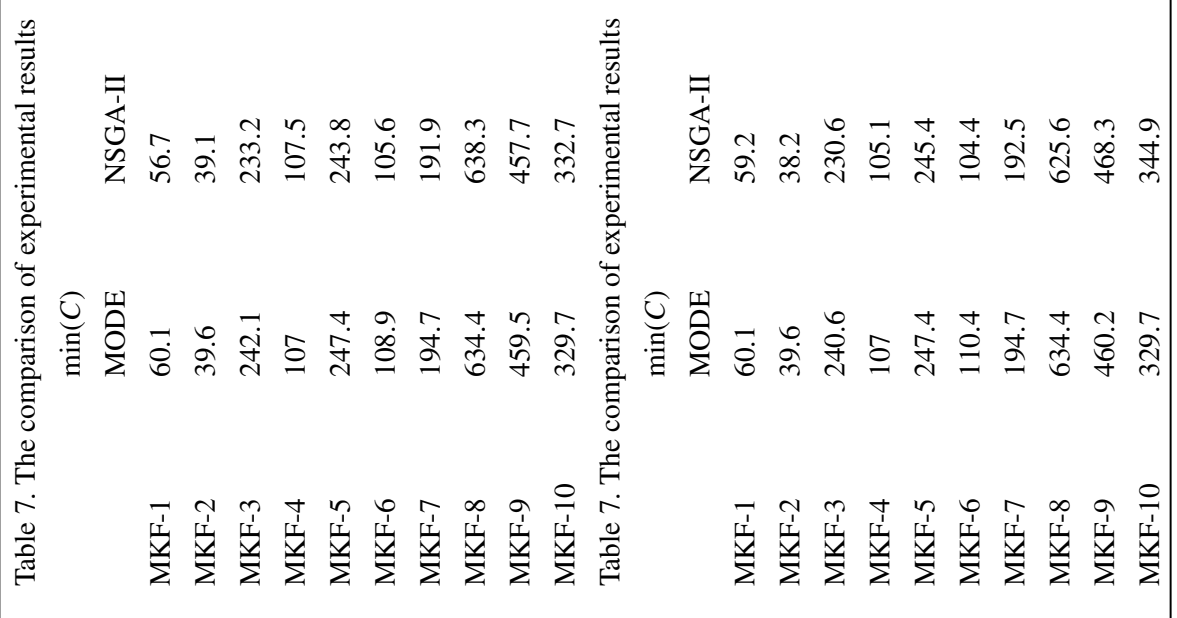

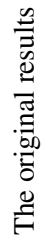

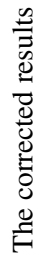

产 


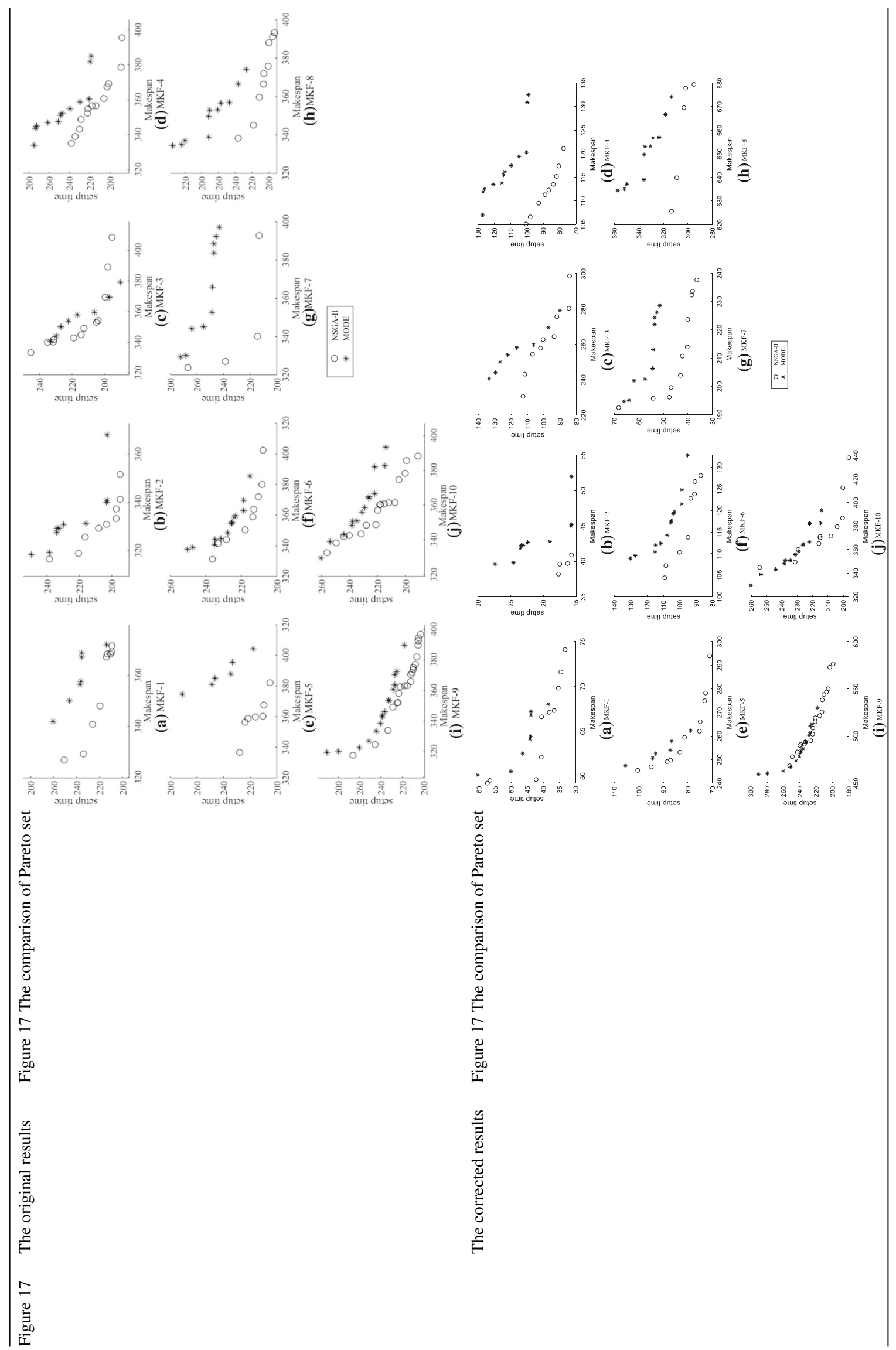


Publisher's Note Springer Nature remains neutral with regard to jurisdictional claims in published maps and institutional affiliations. 